GENGHUANG YANG

WENBIN SUN

XIAYI HAO

YINGMEI ZHANG

LI YANG

and

\title{
Study on generation capacity of small hydropower stations in distribution network
} YANQIU CHE

Small hydropower station, when producing power energy to power system through the distribution network, may lead to the change of the detected current in relay protection and the protection coverage. In this paper, IEEE7 based network is formed in the platform of PSCAD/EMTDC to analyze the effects of distribution network in current protection when a small hydropower station is linked in. The running of relay protection in Section I and II is simulated to obtain the difference of current variation of network with or without small hydropower station. Also the key parameters are calculated to point out the maximum generation capacity of the small hydropower station in case of reliable and sensitive current protection.

Keywords: Small hydropower station, current protection, generation capacity, PSCAD/EMTDC

\subsection{Introduction}

$\mathrm{H}$ ydropower generator of low power in rural area is $\mathrm{h}$

most typical synchronous motor in distribution power network in South China. Small hydropower stations have achieved good economic and environmental benefits [1]. Small hydropower stations are generally distributed in the mountainous areas with abundant water resources. The widely distributed stations result in weak connectivity of the power sources which is quite different from power grid in relay protection. As the relay protection of the common distribution network is relatively simple [2-3]. In rural area of China, the relays or protection devices are not well equipped. When fault takes place and the line fails to work, especially, it is difficult for the distribution network with hydropower stations to recover from the status of fault. There are two ways to overcome the above problem, one is limiting the generation capacity of small hydropower station and the other is upgrading the existing relay protection system of the distribution network. As the upgrading is more

$\overline{\text { Blind peer reviews carried out }}$

Messrs. Genghuang Yang, Wenbin Sun, Xiayi Hao, Yingmei Zhang, Li Yang, Yanqiu Che, School of Automation and Electrical Engineering, Tianjin University of Technology and Education, Tianjin, China. Email: ygenghuang@163.com / 1196419476 @q.com difficult and costs too more compared to limiting the generation capacity, it becomes necessary to study the method of the first way.

At present, low-voltage distribution network of rural area in China are in the type of unilateral power supply mostly, forming in radiation network [4]. The key relay protection of distribution network generally is current protection of threestage, which are no-time-limited current protection (stage I), time-limited current protection (stage II) and timed overcurrent protection (stage III). Current protection (stage I and II) are the main protection of pole lines [5].

In unilateral power supply systems, when fault takes place, only the single power source provides current to the fault point. It is quite simple to remove of the fault by breaking the circuit breaker besides the system. However, the distribution network changes to a multi-power structure when the distributed power source is linked to the distribution network. If the failure in pole line happens, it may cause the sudden change of short-circuit current and its power flow direction, which certainly impacts on reliability of relay protection [6].

The generation capacity of small hydropower stations is studied in the network of IEEE7 in this paper. The influence of the access of small hydropower stations on the protection of current protection stage I and II is analyzed so as to obtain the maximum generation capacity in the distribution network in terms of the accurate operation of the original current protection.

\subsection{Influence of small hydropower access on protection of distribution current}

Fig. 1 shows the typical distribution network of IEEE7. When the three-phase grounded short-circuit fault occurs at points of F1, F2, F3 and F4, the influence of the access of small hydropower stations to the current protection of the distribution network is analyzed. In Fig.1, power system is also called SG (system generator), and the small hydropower station is connected to bus $\mathrm{C}$.

The impedance of pole lines AB, BC, CD, DE, AF and FG are $\mathrm{Z}_{\mathrm{AB}}, \mathrm{Z}_{\mathrm{BC}}, \mathrm{Z}_{\mathrm{CD}}, \mathrm{Z}_{\mathrm{DE}}, \mathrm{Z}_{\mathrm{AF}}, \mathrm{Z}_{\mathrm{FG}}$, and the load impedances at bus $E$ and $G$ are $Z_{L 1}$ and $Z_{L 2}$ respectively. The followings are 


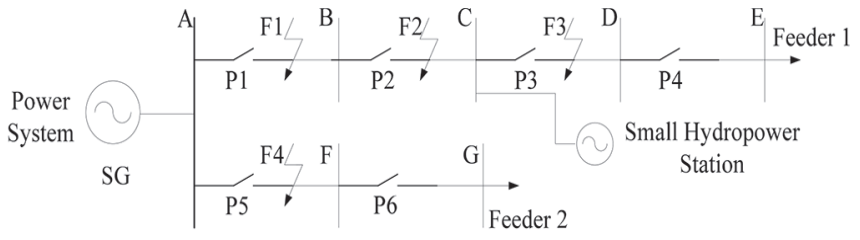

Fig.1 Structure of IEEE7 network with small hydropower

the assumptions in theoretical calculation.

(1) The small hydropower station is considered as the constant model of power source. The power output is always in the maximum limit. The power factor is close to 1 , that is, the apparent power is $\tilde{S}=P+j Q=P$.

(2) The GS is the power system with infinite capacity system, that is, $\mathrm{Z}_{\mathrm{S}}=0$.

(3) All the impedance angles in the pole line are equal to $\beta . E s=\dot{E}_{S} \angle 0^{\circ}, \dot{U}=U \angle \alpha, \dot{E} s$ is the system voltage, $\dot{U}$ is the voltage of bus $\mathrm{C}$ to which the small hydropower station is linked.

\section{A. ShORT-CIRCUIT FAULT OCCURS AT POINT F1}

When the distribution network fails at point F1 in the downstream, the network is simplified to Fig. 2 with ignoring the feeder 2 .

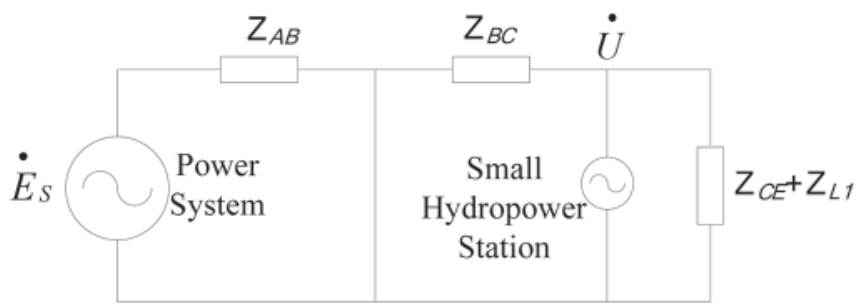

Fig.2 Simplified diagram of three-phase fault at point F1

The short-circuit currents flows through P1 and P2. The calculation of short-circuit currents are shown as follows respectively.

$$
\begin{gathered}
I_{\mathrm{k} 1}=\frac{E_{s}}{Z_{A B}} \\
I_{\mathrm{k} 2}=\frac{U}{\left|Z_{\mathrm{BC}}\right|}=\sqrt{\frac{P \cdot R_{L}}{\left|\mathrm{Z}_{\mathrm{BC}}\right|^{2}+\left|\mathrm{Z}_{\mathrm{CE}}+\mathrm{Z}_{\mathrm{L} 1}\right|\left|\mathrm{Z}_{\mathrm{BC}}\right|}}
\end{gathered}
$$

When F1 is shortend, the fault current flowing through P1 is only related to the system power supply and has no relationship with the accessed small hydropower station. The magnitude of the reverse current $I_{k 2}$ flowing through P2 is proportional to the apparent power output of the small hydropower station. Breaker P2 can accurately remove the fault when $\mathrm{I}_{\mathrm{k} 2}$ exceeds the set value. But the break of breaker P2 will make the downstream of power from small hydropower station to be the isolated island. It does damage to the running of the network.

\section{B. Short-Circuit FAUlt OCCURS AT POINT F2}

When the distribution network fails at point F2 in the downstream, the network is simplified to Fig. 3 with ignoring the feeder 2 .

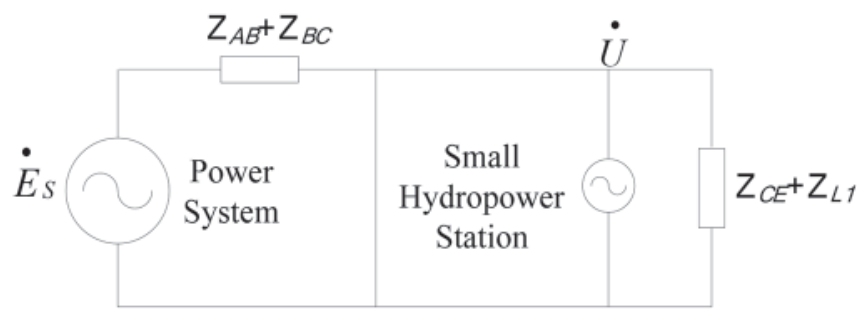

Fig. 3 Simplified diagram of three-phase fault at point F2

The short-circuit current of P1 and P2 only results from the power system. The magnitudes are the same.

$$
I_{\mathrm{k} 1}=I_{\mathrm{k} 2}=\frac{E_{s}}{Z_{A B}+Z_{B C}}
$$

As the small hydropower station has no effect on the short-circuit current of breaker P1 and P2, breaker P1 and P2 can act normally. However, due to the small hydropower station, after the breaker P2 acts, the small hydropower station still injects the short-circuit current to point F2 where the fault arc can not be extinguished. The reclosing always fails and time of power outage is always extended. Therefore, the small hydropower station should timely removed from the network [8].

\section{SHORT-CIRCUIT FAULT OCCURS AT POINT F3}

When the distribution network fails at point F3 in the downstream, the network is simplified to Fig.4 with ignoring the feeder 2 .

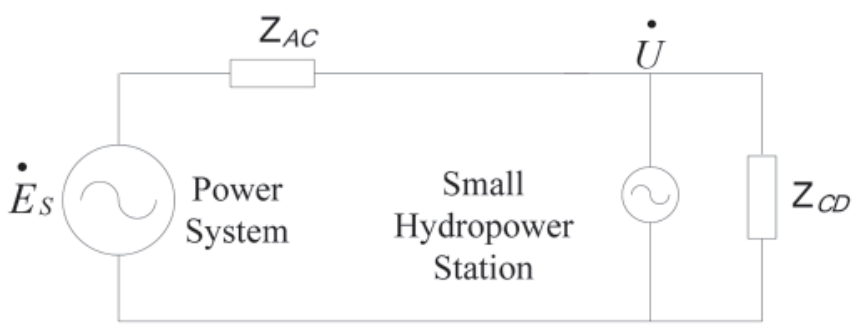

Fig.4 Simplified diagram of three-phase fault at point F3

Due to the difference between the generation capacity of small hydropower station and power system is huge, the phase angles of the two generators are the same, that is $\cos \alpha \approx 1$. The short-circuit currents flowing through P1 and P2 are shown as follows.

$$
\begin{aligned}
& I_{\mathrm{k} 1}=I_{\mathrm{k} 2}=\frac{E_{S}-U}{\left|\mathrm{Z}_{\mathrm{AC}}\right|} \\
& =\frac{E_{S} \cdot\left|\mathrm{Z}_{\mathrm{CD}}\right|+2 E_{S} \cdot\left|\mathrm{Z}_{\mathrm{AC}}\right|-\sqrt{E_{S}^{2} \cdot\left|\mathrm{Z}_{\mathrm{CD}}\right|^{2}+4\left(\left|\mathrm{Z}_{\mathrm{CD}}\right|+\left|\mathrm{Z}_{\mathrm{AC}}\right|\right) \cdot P \cdot\left|\mathrm{Z}_{\mathrm{CD}}\right| \cdot \mathrm{R}_{\mathrm{AC}}}}{2\left(\left|\mathrm{Z}_{\mathrm{CD}}\right|+\left|\mathrm{Z}_{\mathrm{AC}}\right|\right) \cdot\left|\mathrm{Z}_{\mathrm{AC}}\right|}
\end{aligned}
$$

The current flowing through P3 is: 
$I_{\mathrm{k} 3}=\frac{U}{\left|\mathrm{Z}_{\mathrm{CD}}\right|}=\frac{E_{S} \cdot \mathrm{Z}_{\mathrm{CD}} \mid+\sqrt{E_{S}^{2} \cdot\left|\mathrm{Z}_{\mathrm{CD}}\right|^{2}+4\left(\left|\mathrm{Z}_{\mathrm{CD}}\right|+\left|\mathrm{Z}_{\mathrm{AC}}\right|\right) \cdot P \cdot\left|\mathrm{Z}_{\mathrm{CD}}\right| \cdot \mathrm{R}_{\mathrm{AC}}}}{2\left(\left|\mathrm{Z}_{\mathrm{CD}}\right|+\left|\mathrm{Z}_{\mathrm{AC}}\right|\right) \cdot\left|\mathrm{Z}_{\mathrm{CD}}\right|}(5)$

If the small hydropower station is not linked to the distribution network, when fault occurs, the short-circuit current flowing through P1, P2 and P3 is:

$$
I_{\text {int1 }}=\frac{E_{s}}{\left|Z_{A C}\right|+\left|Z_{C D}\right|}
$$

If the small hydropower station is linked to the network, the short-circuit current has the inequality shown as follow because $\mathrm{P}>0$.

$$
\begin{aligned}
& I_{1}<\frac{E_{S} \cdot\left|\mathrm{Z}_{\mathrm{CD}}\right|+2 E_{S} \cdot\left|\mathrm{Z}_{\mathrm{AB}}\right| \cdot \sqrt{E_{S}^{2} \cdot\left|\mathrm{Z}_{\mathrm{CD}}\right|^{2}}}{2\left(\left|\mathrm{Z}_{\mathrm{CD}}\right|+\left|\mathrm{Z}_{\mathrm{AB}}\right|\right) \cdot\left|\mathrm{Z}_{\mathrm{AB}}\right|}=I_{\text {int1 }} \\
& I_{3}>\frac{E_{S} \cdot\left|\mathrm{Z}_{\mathrm{CD}}\right|+\sqrt{E_{S}^{2} \cdot\left|\mathrm{Z}_{\mathrm{CD}}\right|^{2}}}{2\left(\left|\mathrm{Z}_{\mathrm{CD}}\right|+\left|\mathrm{Z}_{\mathrm{AC}}\right|\right) \cdot\left|\mathrm{Z}_{\mathrm{CD}}\right|}=I_{\text {int1 }}
\end{aligned}
$$

When short-circuit fault occurs at point F3, the power flow of breaker P1 and P2 are upstream. The short-circuit current for protection action will less than the current with no small hydropower station. The protection range of breaker $\mathrm{P} 1$ and $\mathrm{P} 2$ reduces. When the breaker P2 is used as the backup protection of the lower line, the protection sensitivity reduces. The current protection is disabled because the shortcircuit current is too small. The short-circuit current through the breaker P3 in the downstream increases due to the current injection from the small hydropower station. The quick-break protection may fall in malfunctioning in the event of a fault in the next line as the protection range expands.

\section{SHORT-CIRCUIT FAULT OCCURS AT POINT F4}

When the fault occurs at point F4 which is located in feeder 2, not only the power system injects the short-circuit current into the F4, but small hydropower station injects the reverse current through breaker P1 and P2 to point F4. The network is simplified as is shown in Fig.5.

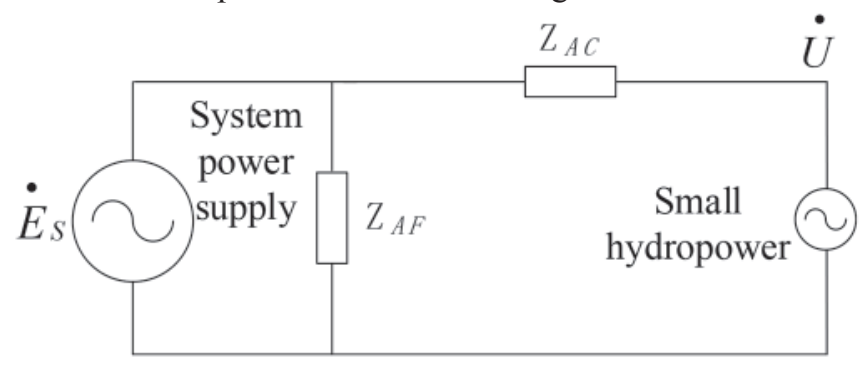

Fig.5 Simplified diagram of three-phase fault at point F4

The short-circuit currents flowing through P1, P2 and P5 are:

$I_{\mathrm{k} 1}=I_{\mathrm{k} 2}=\frac{E_{S}-U}{\left|\mathrm{Z}_{\mathrm{AC}}\right|}$

$=\frac{E_{S} \cdot\left|\mathrm{Z}_{\mathrm{L}}\right|+2 E_{S} \cdot\left|\mathrm{Z}_{\mathrm{AC}}\right|-\sqrt{E_{S}^{2} \cdot\left|\mathrm{Z}_{\mathrm{L}}\right|^{2}+4\left(\left|\mathrm{Z}_{\mathrm{L}}\right|+\left|\mathrm{Z}_{\mathrm{AC}}\right|\right) \cdot P \cdot\left|\mathrm{Z}_{\mathrm{L}}\right| \cdot \mathrm{R}_{\mathrm{AC}}}}{2\left(\left|\mathrm{Z}_{\mathrm{L}}\right|+\left|\mathrm{Z}_{\mathrm{AC}}\right|\right) \cdot\left|\mathrm{Z}_{\mathrm{AC}}\right|}$

$$
\begin{aligned}
& I_{k 5}=\frac{E_{s}}{Z_{A F}} \\
& I_{1}<\frac{E_{S} \cdot\left|Z_{\mathrm{L}}\right|+2 E_{S} \cdot\left|\mathrm{Z}_{\mathrm{AB}}\right|-\sqrt{E_{S}^{2} \cdot\left|\mathrm{Z}_{\mathrm{L}}\right|^{2}}}{2\left(\left|\mathrm{Z}_{\mathrm{L}}\right|+\left|\mathrm{Z}_{\mathrm{AB}}\right|\right) \cdot\left|\mathrm{Z}_{\mathrm{AB}}\right|}=I_{\text {int1 }}
\end{aligned}
$$

Only breaker P5 on the feeder 2 can remove the fault. Ideally, if the network does not consider the impedance, small hydropower station's access will not affect the bus voltage and the action of breaker P5. However, in engineering, when taking into account the superposition of impedance of power system and the small hydropower station, the short-circuit current through breaker P5 increases and its protection range expands. The current protection may lose selectivity [9]. At the same time, the current flowing through breaker P1 and P2 on the feeder 1 decreases where the small hydropower station is located, and the reverse current of small hydropower station can be generated in severe cases. The non-fault line protection is disabled and the power failure range expands.

\subsection{Determination of protection parameters of distribution networks without small hydropower}

In Fig.1, IEEE7 network module is built based on PSCAD/ EMTDC. The three-phase grounded short-circuit fault at the end of each line is simulated, and the corresponding parameters in time-limited current protection are provided. The parameters of the distribution network are shown in Tables 1, 2 and 3. Among them, the positive sequence impedance of the line is $0.104+\mathrm{j} 1.270 \Omega$, and the negative sequence impedance is $0 \Omega$, and the zero sequence impedance is $0.900+\mathrm{j} 3.428 \Omega$, and towers are installed every 60 meters.

TABLE 1: LINE PARAMETERS OF DISTRIBUTION NETWORK

\begin{tabular}{cccc}
\hline $\begin{array}{c}\text { Name of } \\
\text { line }\end{array}$ & $\begin{array}{c}\text { Length of } \\
\text { line }(\mathrm{km})\end{array}$ & $\begin{array}{c}\text { Name of } \\
\text { line }\end{array}$ & $\begin{array}{c}\text { Length of } \\
\text { line }(\mathrm{km})\end{array}$ \\
\hline $\mathrm{AB}$ & 3 & $\mathrm{DE}$ & 10 \\
$\mathrm{BC}$ & 5 & AF & 2 \\
$\mathrm{CD}$ & 8 & FG & 8 \\
\hline
\end{tabular}

TABLE 2: LOAD OF FEEDERS

\begin{tabular}{ccc}
\hline $\begin{array}{c}\text { Name of } \\
\text { feeder }\end{array}$ & $\begin{array}{c}\text { Active } \\
\text { power (MW) }\end{array}$ & $\begin{array}{c}\text { Reactive } \\
\text { power (MVAR) }\end{array}$ \\
\hline Feeder 1 & 2 & 4 \\
Feeder 2 & 0.9 & 1.8 \\
\hline
\end{tabular}

TABle 3: Power SUPPly PARAMETERS OF Distribution NETWORK

\begin{tabular}{ccccc}
\hline $\begin{array}{c}\text { Name of } \\
\text { power } \\
\text { supply }\end{array}$ & $\begin{array}{c}\text { Reference } \\
\text { voltage }(\mathrm{kV})\end{array}$ & $\begin{array}{c}\text { capacity } \\
(\mathrm{MVA})\end{array}$ & $\begin{array}{c}\text { Minimum } \\
\text { reactance } \\
(\mathrm{H})\end{array}$ & $\begin{array}{c}\text { Maximum } \\
\text { reactance } \\
(\mathrm{H})\end{array}$ \\
\hline SG & 10.5 & 150 & 0.0003 & 0.0004 \\
\hline
\end{tabular}

\section{E. NO-TIME-LIMIT CURRENT PROTECTION}

When the current through the breaker increases to the threshold value, no-time-limit current protection delivers the 
control signal for instantaneous action. The role is to ensure removing the fault on the line [5] in any case. The grounded current in case of the three-phase short-circuit fault at each end of the line is shown in Table 4 when simulation system works in the maximum running mode.

TABLE 4: GROUNDED CURRENT IN CASE OF THREE-PHASE SHORT CIRCUIT FAULT AT EACH SEGMENT

\begin{tabular}{cccc}
\hline line & $\begin{array}{c}\text { Fault current } \\
(\mathrm{kA})\end{array}$ & line & $\begin{array}{c}\text { Fault current } \\
(\mathrm{kA})\end{array}$ \\
\hline $\mathrm{AB}$ & 2.758 & $\mathrm{DE}$ & 0.661 \\
$\mathrm{BC}$ & 1.373 & $\mathrm{AF}$ & 2.771 \\
$\mathrm{CD}$ & 0.900 & FG & 1.331 \\
\hline
\end{tabular}

In quick-break protection, the calculation the threshold value setting formula and the minimum protection range formula [2] is shown as follows.

$$
\begin{aligned}
& I_{a c t 1}^{\mathrm{I}}=K_{\mathrm{rel}}^{\mathrm{I}} I_{k B \max } \quad\left(K_{\mathrm{rel}}^{\mathrm{I}}=1.2\right) \\
& I_{\text {set. } 1}^{\mathrm{U}}=K_{r e l}^{\mathrm{U}} I_{\text {set. } 2}^{\mathrm{I}} \quad\left(K_{r e l}^{\mathrm{U}}=1.1\right)
\end{aligned}
$$

Combined with Table 4, threshold setting value of current protection section I and the minimum protection range is shown in Table 5.

\begin{tabular}{ccc} 
TABLE 5: THRESHOLD SETTING IN QUICK-BREAK CURRENT PROTECTION \\
\hline Protection & $\begin{array}{c}\text { Threshold setting } \\
\text { in quick-break } \\
\text { protection (kA) }\end{array}$ & $\begin{array}{c}\text { Range of } \\
\text { protection }\end{array}$ \\
\hline 1 & 3.3096 & $43 \%$ \\
2 & 1.6482 & $51 \%$ \\
3 & 1.08 & $49 \%$ \\
4 & 0.7938 & $53 \%$ \\
5 & 3.3252 & $64 \%$ \\
6 & 1.5978 & $33 \%$ \\
\hline
\end{tabular}

\section{F. TIME-LIMIT CURRENT PROTECTION}

No-time-limit current protection can only protect a part of the line, the rest of the part will rely on the protection with time-limit protection to cut off the fault, so that the current protection section I and II of the pole line constitute the main line. The threshold setting value of current protection for the speed-limit quick-break protection is [5].

$$
I_{\text {set. } 1}^{\amalg}=K_{r e l}^{\amalg} I_{\text {set. } 2}^{\mathrm{I}} \quad\left(K_{\text {rel }}^{\amalg}=1.1\right)
$$

In order to ensure that the speed-limit protection is sufficient to the full length of the pole line, generally in the smallest running mode of power system, two-phase shortcircuit fault analysis is used to verify the sensitivity. The simulated fault current and time-limit overcurrent protection settings and the corresponding sensitivity are shown in Table 6.

According to the simulation and calculation, in the distribution network with small hydropower station, the
Table 6: Setting VAlue of TIME-LIMITED QUiCK-BREAK CURRENT PROTECTION

\begin{tabular}{cccc}
\hline Protection & $\begin{array}{c}\text { Breaking } \\
\text { current setting } \\
\text { in time-limit } \\
\text { protection (kA) }\end{array}$ & $\begin{array}{c}\text { Current at the } \\
\text { end of } \\
\text { protection } \\
\text { range when } \\
\text { two-phase } \\
\text { short-circuit } \\
\text { fault (kA) }\end{array}$ & Sensitivity \\
\hline 1 & 1.8130 & 2.3103 & $51.1 \%$ \\
2 & 1.1880 & 1.9510 & $60.9 \%$ \\
5 & 0.8732 & 1.7522 & $49.8 \%$ \\
\hline
\end{tabular}

current protection of pole line I and II meets the requirements.

\subsection{Generation capacity analysis}

From the above analysis, it can be seen that the access of small hydropower station not only lead to the distribution of the short circuit current, but also lead to the change of the direction of current flow in the corresponding pole line of the distribution network. The above results in making the protection malfunction and the fault range expand, which finally endanger the stable running of the power grid. Generation capacity refers to the maximum supply value of the distributed power source to the power system when the distributed power source is linked to the distribution network, without changing the principles and devices of relay protection of the network. The protection for the whole distribution network is reliable [3].

The followings are the simulation and discussion of how the generation capacity of small hydropower station impacts short-circuit current when different located fault occurs. The generation capacity is obtained. The simulation topology diagram is shown in Fig.1, in which the small hydropower station is linked to point $\mathrm{C}$. In the simulation, the excitation system of a small hydropower generator is AC1A module, and the water turbine is TUR1 module, and the water turbine controller is GOV1 module in PSCAD/EMTDC.

\section{G. SHORT-CIRCUIT FAULT OCCURRED AT POINT F1}

From the above analysis, it can be seen that when a shortcircuit fault occurred at point F1, the small hydropower station injects the fault current through breaker P2 to the fault point. When the fault current exceeds the threshold value, it leads to the fault operation of the breaker P2 in current protection section II, which mainly affects the action of breaker P2, and has little effect on breaker P1.

It can be seen from Fig.6, the generation capacity should be less than 11MVA in order to make breaker $\mathrm{P} 2$ be reliable to act.

\section{H. SHORT-CIRCUIT FAULT OCCURRED AT POINT F2}

From the above analysis, it can be seen that when a shortcircuit fault occurs at point F2, the short-circuit current 
TABLE 7: SHorT-CIRCUIT CURRENT FLOWING THROUGH DIFFERENT SEGMENT WHEN POINT F1 IS FAULTY

\begin{tabular}{ccccc}
\hline $\mathrm{S}_{\mathrm{DG}} / \mathrm{MA}$ & $\mathrm{I}_{\mathrm{DG}} / \mathrm{KA}$ & $\mathrm{I}_{1} / \mathrm{KA}$ & $\mathrm{I}_{2} / \mathrm{KA}$ & $\mathrm{I}_{3} / \mathrm{KA}$ \\
\hline 0 & 0 & 2.7583 & 0.0114 & 0.0114 \\
4 & 0.6495 & 2.7720 & 0.6628 & 0.0140 \\
8 & 1.0520 & 2.7320 & 1.0543 & 0.0220 \\
12 & 1.3240 & 2.6970 & 1.3188 & 0.0283 \\
14 & 1.4277 & 2.6839 & 1.4199 & 0.0302 \\
\hline
\end{tabular}

$\left(\mathrm{S}_{\mathrm{DG}}\right.$ is the generation capacity of small hydropower station, $\mathrm{I}_{\mathrm{DG}}$ represents the current of small hydropower generation, $\mathrm{I}_{1}, \mathrm{I}_{2}, \mathrm{I}_{3}$ are P1, P2, P3 detected current)

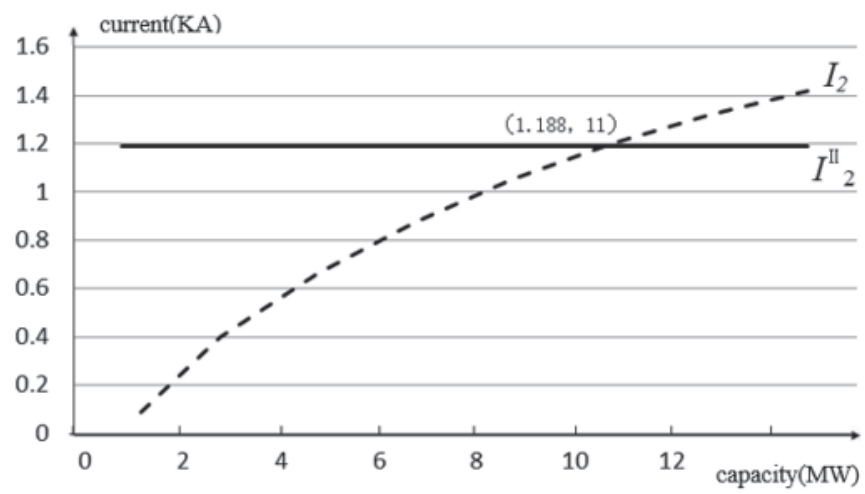

Fig.6 Generation capacity of small hydropower station when point F1 is faulty

flowing through breaker P1 and breaker P2 is provided by the power system, and the small hydropower station does not affect the current protection. As the current protection is used for removal of fault from system power in the previously mentioned measure, it is unacceptable that the small hydropower station is still linked to the fault point on the distribution network.

\section{SHORT-CIRCUIT FAULT OCCURRED AT POINT F3}

From the above analysis, it can be seen that when a shortcircuit fault occurs at point F3, the short-circuit current flowing through breaker P2 is formed by the current from power system and the hydropower station. The quick-break protection range is reduced [6]. The small hydropower station linked to bus $\mathrm{C}$ does not affect the action of breaker P2. However, the access of small hydropower station results in the increase of the current flowing through breaker P3 and the enlargement of its protection range. The above change can cause the protection range of breaker P3 in section I to stretch out its setting range and to lose the selectivity of breaker $\mathrm{P} 4$ of the line DE.

When $\mathrm{I}_{3}^{\mathrm{I}}=1.08$, Table 8 is plotted as Fig.7. If breaker P3 does not malfunction, the generation capacity should be less than 11.2MVA.

\section{J. Short-Circuit Fault OCCURRED AT POINT F4}

On the adjacent line of feeder 2, the small hydropower station injects current to the fault point F4 through breaker
TABle 8: Short-Circuit CURRENT FLOWING THROUGH DIFFERENT SEGMENT WHEN POINT F3 IS FAULTY

\begin{tabular}{ccccc}
\hline $\mathrm{S}_{\mathrm{DG}} / \mathrm{MA}$ & $\mathrm{I}_{\mathrm{DG}} / \mathrm{KA}$ & $\mathrm{I}_{1} / \mathrm{KA}$ & $\mathrm{I}_{2} / \mathrm{KA}$ & $\mathrm{I}_{3} / \mathrm{KA}$ \\
\hline 0 & 0 & 0.9020 & 0.9020 & 0.6892 \\
4 & 0.4910 & 0.7700 & 0.7700 & 0.8568 \\
8 & 0.8488 & 0.6823 & 0.6820 & 0.9150 \\
12 & 1.1048 & 0.6318 & 0.6320 & 1.5094 \\
14 & 1.2050 & 0.6142 & 0.6142 & 1.5608 \\
\hline
\end{tabular}

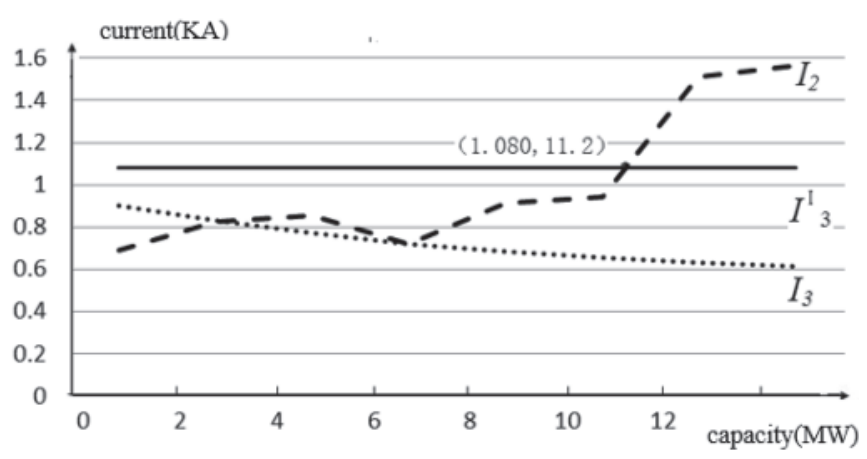

Fig.7 Generation capacity of small hydropower station when point F3 is faulty

P1 and P2 when a short-circuit fault occurs at point F4. Although the currents flowing through breaker P1 and P2 are the same, the threshold value of breaker P2 is relatively small, so the operation of breaker P2 is necessary for analysis. The access of mall hydropower station also increases short-circuit current pouring into breaker P5.

Combined with Table 9, when $\mathrm{I}_{2}^{\mathrm{II}}=1.18800 \mathrm{I}^{\mathrm{I}}{ }_{5}=3.3252$, the short-circuit current through breaker P2 and P5 is described as Fig.8.

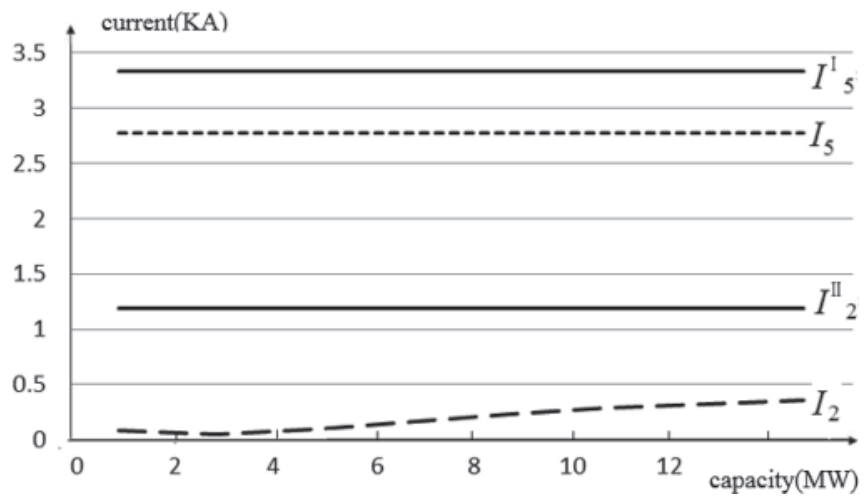

Fig.8 Generation capacity of small hydropower station when point F4 is faulty

It can be seen from Fig.8, the access of small hydropower station produces an effect on breaker P5 less than P2 in shortcircuit current. With the variation of generation capacity of small hydropower station, the short-circuit current through breaker P2 caused by reverse power flow of generator is small. Because of the adjacent feeder fault and malfunction, breaker P5 quick-break protection dose not malfunction. 
TABLE 9: SHorT-CIRCUIT CURRENT FLOWING THROUGH DIFFERENT SEGMENT WHEN POINT F4 IS FAULTY

\begin{tabular}{ccccc}
\hline $\mathrm{S}_{\mathrm{DG}} / \mathrm{MA}$ & $\mathrm{I}_{\mathrm{DG}} / \mathrm{KA}$ & $\mathrm{I}_{1} / \mathrm{KA}$ & $\mathrm{I}_{2} / \mathrm{KA}$ & $\mathrm{I}_{5} / \mathrm{KA}$ \\
\hline 0 & 0 & 0.0843 & 0.0845 & 2.7710 \\
4 & 0.1521 & 0.090 & 0.0900 & 2.7726 \\
8 & 0.2975 & 0.2323 & 0.2324 & 2.7714 \\
12 & 0.3903 & 0.3196 & 0.3226 & 2.7700 \\
14 & 0.4212 & 0.3502 & 0.3534 & 2.7693 \\
\hline
\end{tabular}

( $\mathrm{I}_{5}$ is the current detected by breaker P5)

To sum up, the distribution network working in the traditional current protection runs reliably when the maximum generation capacity of small hydropower station is less than 11MVA.

\subsection{Conclusion}

In summary, the access of hydropower stations to low-voltage distribution network result in the impact of its relay protection which are:

1. Protection sensitivity decreases. When short-circuit faults occurs downstream of small hydropower station, the sensitivity of current protection will reduces and the protection range will be smaller than that in upstream protection, which may make the protection refused to act.

2. Protection directionality loses. When the fault occurs upstream of breaker P2, the small hydropower station will inject current to form the fault current, which may be greater than the threshold value in severe cases, resulting in malfunction of breaker P2. When the adjacent line fails in faults, the small hydropower station will inject current through P1 and P2, and causes fault operation of current protection.

3. Protection in downstream loses match. When a short-circuit fault occurs in the lower reaches of the small hydropower station, the current of power system superimposed the injection current of the small hydropower station, the protection range may extend to the next protection zone, result in mismatch of the cooperation in current protection section I and II.

As the above mentioned, simulation and analysis under the principles of ensuring the reliability of the original relay protection shows that the generation capacity of small hydropower station is related to its location. Also the maximum generation capacity of small hydropower station is based on the principles.

\subsection{Acknowledgments}

This paper is supported by the project of Tianjin University of Technology and Education (K-GD2014-1023).

\subsection{References}

[1] Yun Lu; Bo Gao (2014): Analysis of Distribution Network Fault and Protection Range with Distributed Power Supply, Journal of Shanghai University of Electric Power, Vol. 30. pp511-514.

[2] Fuhua Jiang; Xiaozhong Du (2004): China's small hydropower development status and problems, China Rural Water and Hydropower, Vol. 1. pp82-86..

[3] Peng Xue (2014): The main problems and solutions of the improvement and expansion of small and medium hydropower stations, China rural water power and hydropower, Vol.1.pp133-136.

[4] Ming Zhao; Haiqing Yan; Xiaohong Liu (2014): Study on Rural Distribution Network Protection Algorithm with Distributed Power Supply, China Rural Water and Hydropower, Vol. 1. pp172-179.

[5] Chao Zhang; Jianren Ji (2006): Influence of distributed generation on feeder protection of distribution network, Relays, Vol. 34. pp9-12,

[6] Limin Huo (2008): Power System Relay Protection. Beijing: China Electric Power Press.

[7] Wang Jianghai (2010): Study on the Access Capacity of Distributed Power Supply Considering Relay Protection in Distribution Network, Proceeding of the CSEE, Vol. 30. pp37-43..

[8] Lulu Chen (2014): Distribution network protection scheme with distributed power suppl, Nanjing: Nanjing University of Science and Technology.

[9] Fanghong Wang (2011): Study on relay protection of small hydropower grid-connected distribution network, Hangzhou: Zhejiang University.

\title{
INDIAN JOURNAL OF POWER \& RIVER VALLEY DEVELOPMENT
}

\author{
Special Issue on \\ OTPC - A SUCCESS STORY \\ For copies, please contact: \\ The Manager \\ BOOKS \& JOURNALS PVT. LTD. \\ 62 Lenin Sarani, Kolkata 700013 \\ E-mail: bnjournals@gmail.com
}

